Konservasi keanekaragaman hayati dalam dunia pendidikan Dwi N. Adhiasto

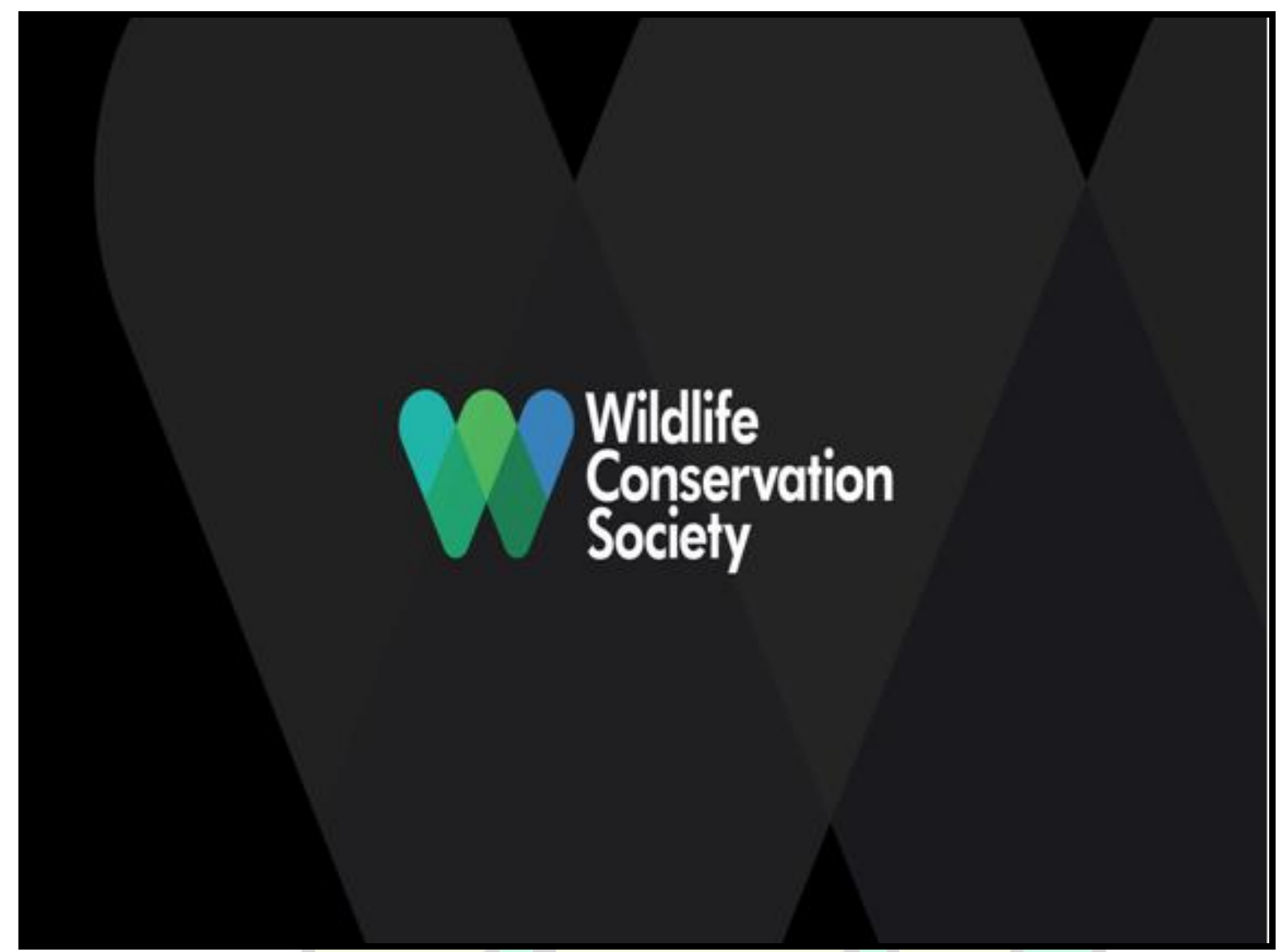

\title{
KONSERVASI KEANEKARAGAMAN HAYATI dalam DUNIA PENDIDIKAN
}

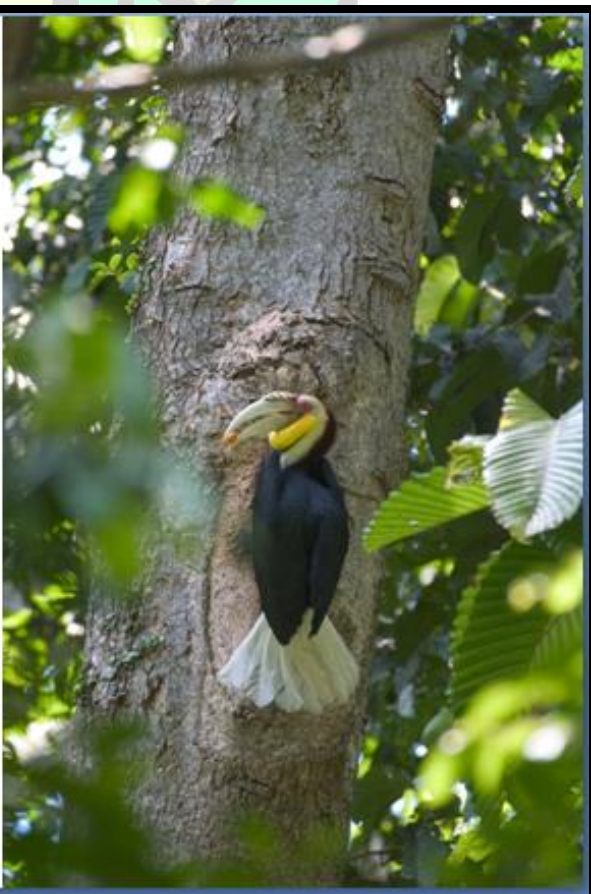




\section{Indonesia}

- 17,000 Islands, 990 permanently inhabited

- One of 17 mega biodiversity countries

- $\mathbf{5 6 6}$ protected areas (36 million hectares)

- Conserve more than $\mathbf{9 0 0}$ species (new list)

- Threatened by extinction

\section{$\prod_{\text {wes }}^{\infty}$}

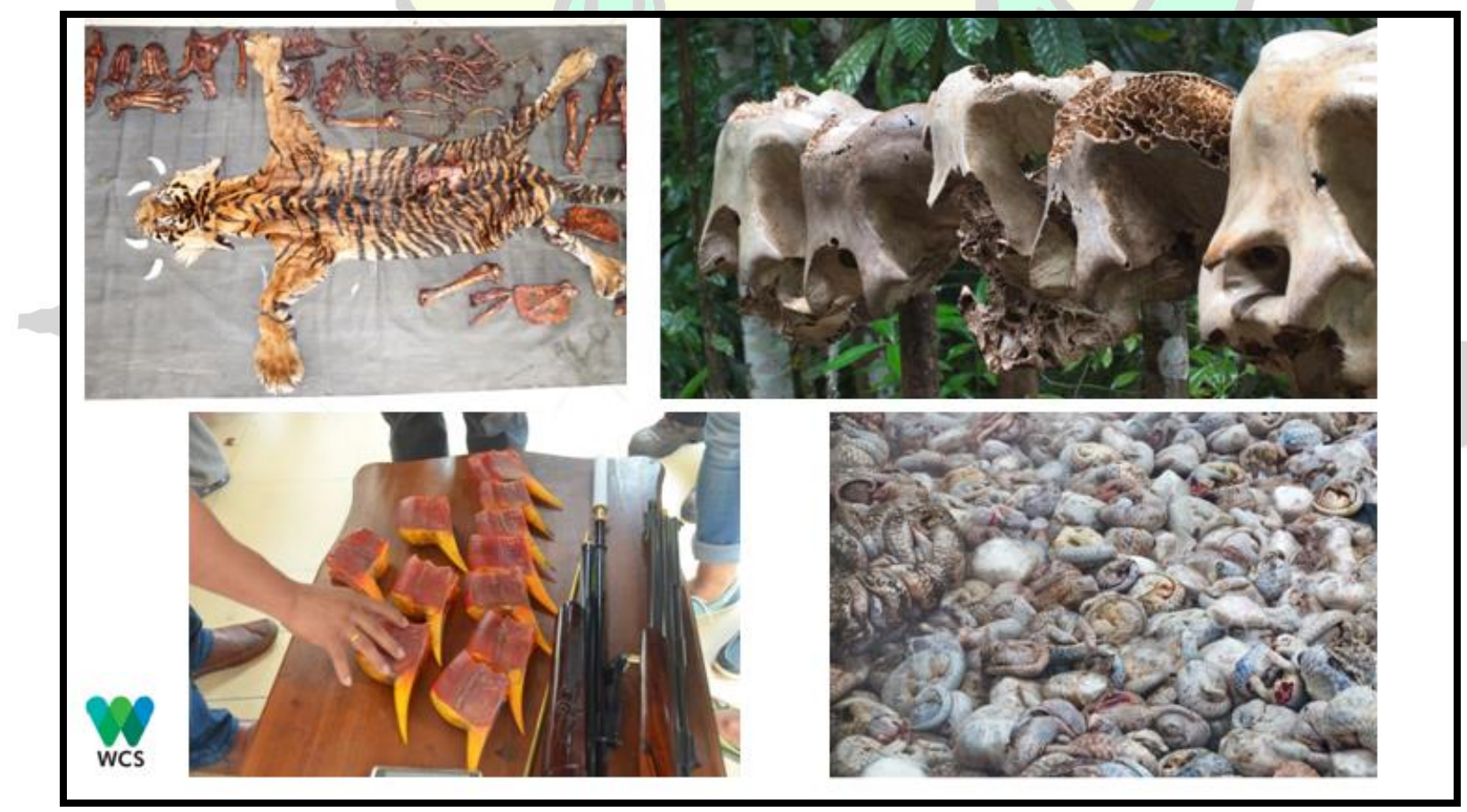




\section{Konservasi}

- Perlindungan : Melindungi supava tidak mengalami degradasi

- Pengawetan : Mengawetkan supava tidak merubah fungsi dan bentuk

- Pemanfaatan : Pemanfaatan berkelanjutan (sustainable use) untuk keseiahteraan

\section{Isu Konservasi SDA}

- Degradasi hutan (perambahan, logging, alih fungsi)

- Konflik pemanfaatan lahan

- Pencemaran lingkungan

- Pertambangan

- Biopiracy

- Perburuan dan peredaran ilegal hidupan liar

- Konflik manusia - satwa liar

- Status perlindungan satwa

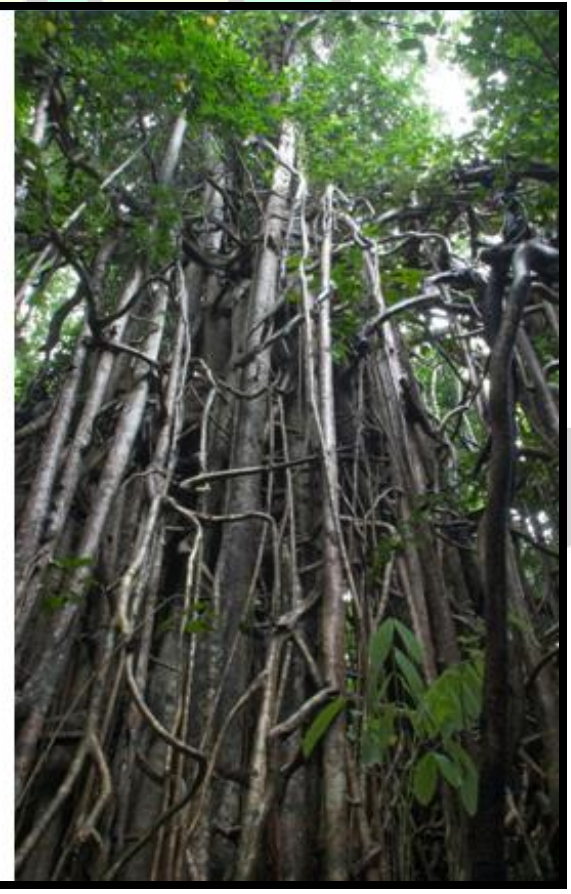




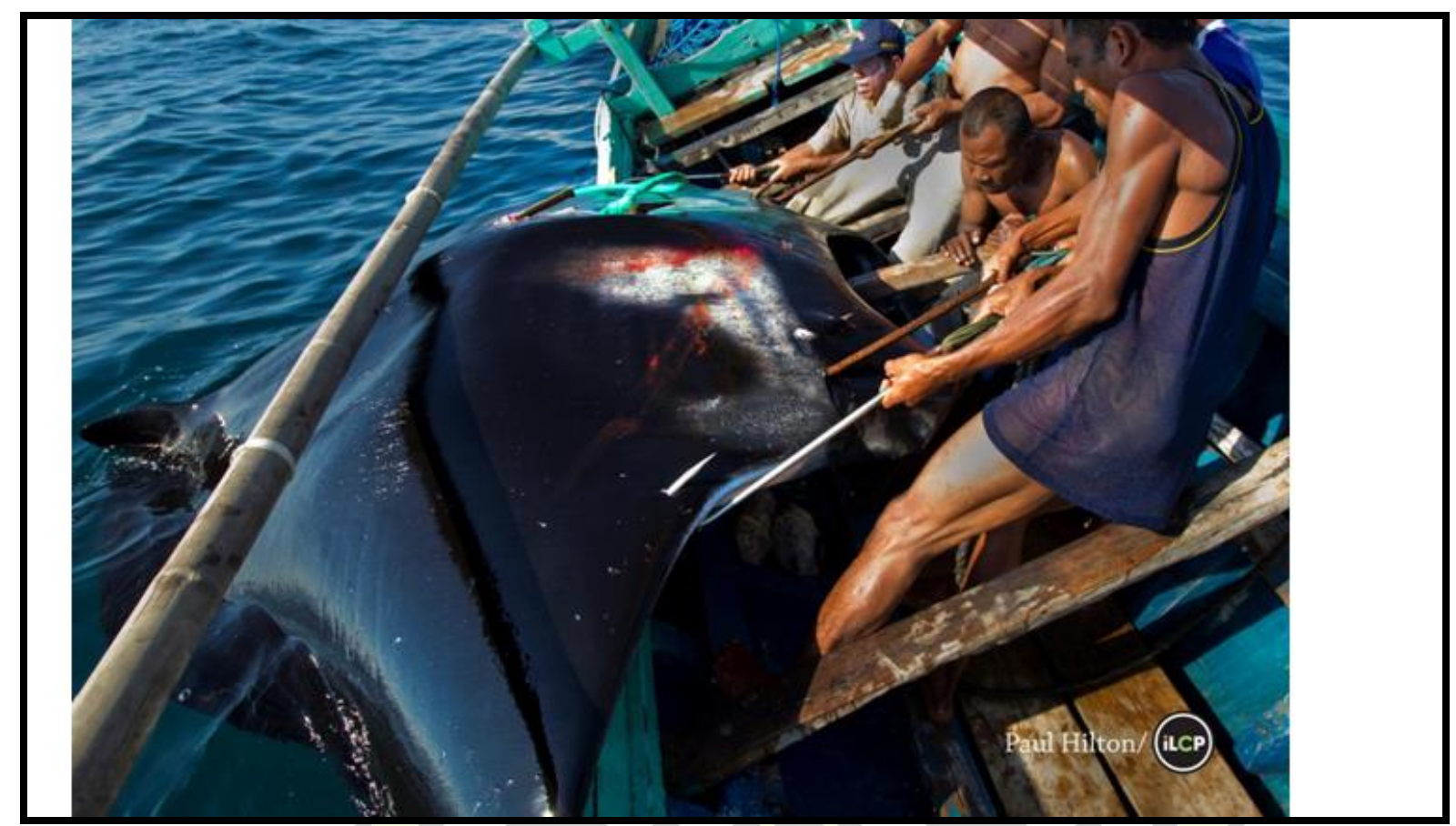

\section{Tantangan konservasi}

- Jumlah penduduk yang besar

- Level pendidikan beragam - mempengaruhi pola pikir (55 persen anak usia 15 tahun di Indonesia secara fungsional buta huruf)

- Pendidikan konservasi tidak dari dini membentuk kebiasaan/karakter buruk terhadap lingkungan

- Dunia akademisi kurang memperhatikan konservasi dalam pembentukan karakter muridkurikulum kurang mengakomodir isu konservasi

- Penenegakan hukum yang adil dan menciptakan efek jera

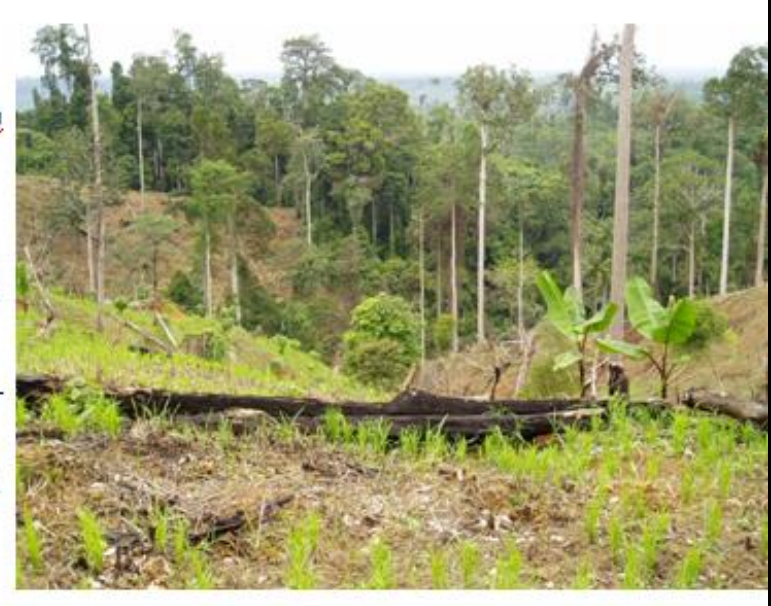




\section{Pendidikan Konservasi}

- Sebaiknva diwuiudkan dengan kegiatan penanaman doktrin, penvebarluasan gagasan, serta aksi konservasi

- Mengarahkan dan merubah perilaku tidak peduli meniadi pro konservasi

- Merupakan kegiatan pencegahan keiahatan (crime prevention/preventive)

- Lebih murah dibandingkan kegiatan penanggulangan (reactive) dan pemulihan (recovery)

- Dilakukan di semua tahapan pendidikan (dasar - laniut), dengan kurikulum yang akomodatif

\section{Pendidikan Formal}

- Pendidikan di sekolah (Biologi, IPA, IPS, Geografi)

- Pendidikan dan Latihan bagi professional/profesi (Diklat di KLHK, Kejaksaan, Kehakiman, Bea Cukai, Kepolisian, Karantina)

- Sekolah Alam (Boarding school)

- Peningkatan akuntabilitas dan kualitas pengajar

\section{Pendidikan Non-Formal}

- Komunitas pecinta alam

- Kelompok studi (kelautan, herpetology)

- Pusat Studi

- Ekstra kurikuler/unit kegiatan mahasiswa 

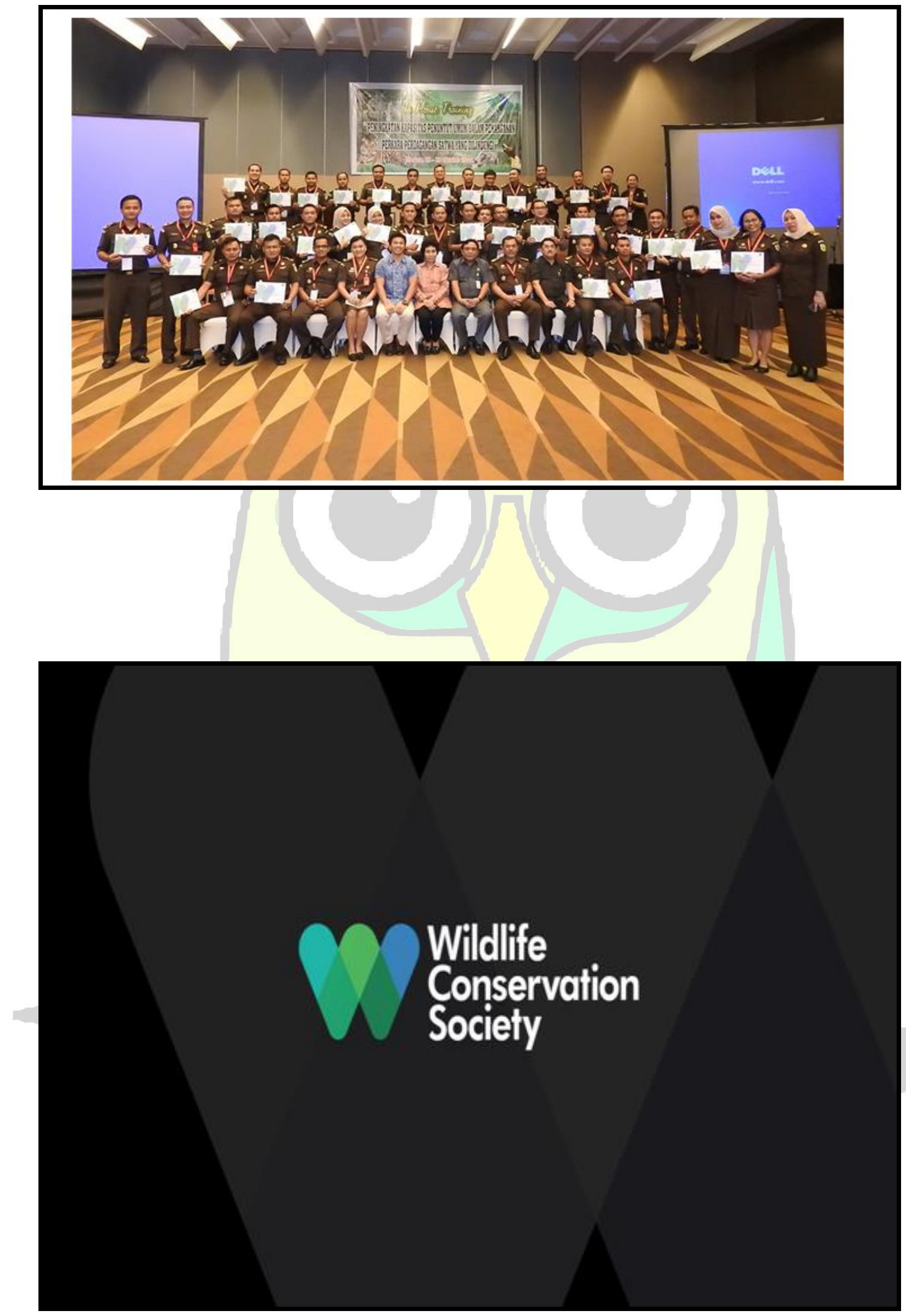